\title{
Roles of coagulation pathway and factor Xa in rat mesangioproliferative glomerulonephritis
}

\author{
Keiko Nomura ${ }^{1}$, Ning Liu ${ }^{1}$, Kojiro Nagai ${ }^{2,3}$, Takamichi Hasegawa ${ }^{4}$, Ikei Kobayashi ${ }^{1}$, Fumiaki Nogaki ${ }^{1}$, Misa Tanaka ${ }^{1}$, \\ Hidenori Arai $^{2}$, Atsushi Fukatsu ${ }^{3}$, Toru Kita ${ }^{1}$ and Takahiko Ono ${ }^{4}$
}

Tissue factor initiates the extrinsic coagulation pathway by activating coagulation factor $\mathrm{X}$ to factor $\mathrm{Xa}$, and factor $\mathrm{V}$ is a cofactor for the prothrombin activation by factor Xa. As factor Xa is known to promote the proliferation of mesangial cells in culture, the roles of the coagulation pathway and factor Xa were studied in an animal model of mesangioproliferative glomerulonephritis (MsPGN). MsPGN was induced in Wistar rats by an intravenous injection of anti-Thy 1.1 monoclonal antibody, OX-7. To clarify the role of factor Xa in MsPGN, a specific factor Xa inhibitor, DX-9065a, was injected intravenously at 2.5 or $10 \mathrm{mg} / \mathrm{kg}$ at the same time as OX-7, and kidney involvement was assessed by immunohistological analyses. We also examined p44/42 mitogen-activated protein (MAP) kinase activation. Time-course study revealed that expressions of tissue factor, factor $\mathrm{V}$, and protease-activated receptor 2 (PAR2) were peaked on day 3, followed by factor $\mathrm{X}$ accumulation and mesangial proliferation. DX-9065a treatment significantly ameliorated proteinuria in a dose-dependent manner on day 8. Histological analyses showed a significant reduction in the size of glomeruli, the total number of glomerular cells, and crescent formation by DX-9065a treatment. Macrophage infiltration, which was rapidly observed on day 1 in disease control rats was not inhibited on days 1-3 by DX-9065a treatment, however it was suppressed on days 58. The deposition of fibrin, the number of PCNA-positive cells, and phosphorylation of p44/42 MAP kinase were markedly increased in the disease control group, whereas they were significantly reduced in the treatment group. Tissue factor and factor $\mathrm{V}$ induction may accelerate MsPGN through the activation and accumulation of factor $\mathrm{X}$ via proinflammatory and procoagulant mechanisms, and the inhibition of factor Xa would be a promising method to regulate the disease process. Laboratory Investigation (2007) 87, 150-160. doi:10.1038/labinvest.3700502; published online 18 December 2006

KEYWORDS: factor X; factor V; PAR2; DX-9065a; inflammation

A pathogenic role for locally accelerated coagulation causing the deposition of fibrin has been indicated in various active mesangioproliferative glomerulonephritis $(\mathrm{MsPGN}) .^{1}$ In a previous study, we showed that coagulation factor $\mathrm{V}$ is colocalized with fibrin in the mesangial area in an active type of IgA nephropathy with mesangial cell proliferation. ${ }^{2}$ In another in vitro study, we observed that the coagulation process proceeds on the surface of cultured mesangial cells via the expression of factor $\mathrm{V}$ after the stimulation of an inflammatory cytokine TNF- $\alpha$ with exogenous factor $\mathrm{Xa}^{3}$ Furthermore, Monno et $a l^{4}$ have shown that factor Xa directly promotes mesangial cell proliferation in vitro. Factor $\mathrm{Xa}$ contributes to the release of cytokines, and induces the expression of adhesion molecules and proliferation in en- dothelial cells. ${ }^{5,6}$ We have also shown that factor Xa induces cellular proliferation through the activation of extracellular regulated kinase (ERK) 1/2 via protease-activated receptor 2 (PAR2) in cultured human mesangial cells, and that DX9065a, a small synthetic molecule, and a specific Xa inhibitor, suppresses their proliferation. ${ }^{7}$ DX-9065a can competitively inhibit human factor Xa (Ki value: $0.041 \mu \mathrm{M}){ }^{8}{ }^{8}$ Recently reported effects of this drug include activity to regulate coagulation and proliferation ${ }^{9}$ in vivo and in vitro. ${ }^{10}$

Nephritis induced by anti-Thy 1.1 monoclonal antibody in rats is recognized as an experimental model of MsPGN, and is referred to as Thy- 1 nephritis. ${ }^{11}$ Thy- 1 antigen, originally identified as an antigen of thymocytes, also appears in rat glomerular mesangial cells. Thy-1 nephritis is characterized

\footnotetext{
${ }^{1}$ Department of Cardiovascular Medicine, Kyoto University Graduate School of Medicine, Kyoto, Japan; ${ }^{2}$ Department of Geriatric Medicine, Kyoto University Graduate School of Medicine, Kyoto, Japan; ${ }^{3}$ Department of Nephrology, Kyoto University Graduate School of Medicine, Kyoto, Japan and ${ }^{4}$ Division of Molecular Medicine, University of Shizuoka School of Pharmaceutical Sciences, Shizuoka, Japan

Correspondence: Dr T Ono, MD, Division of Molecular Medicine, University of Shizuoka School of Pharmaceutical Sciences, 52-1 Yada, Suruga-ku, Shizuoka City 422-8526, Japan. E-mail: ono@u-shizuoka-ken.ac.jp

Received 18 May 2006; revised 3 October 2006; accepted 17 October 2006; published online 18 December 2006
} 
by initial mesangiolysis, platelet and monocyte/macrophage infiltration, and subsequent mesangial cell proliferation and mesangial matrix expansion. It has been reported that acute injury of the glomerulus in Thy-1 nephritis is mainly initiated by necrosis ${ }^{12}$ and apoptosis of mesangial cells, and is often accompanied by cellular crescent formation. ${ }^{13}$ Subsequent mesangial cell proliferation is an important pathophysiological phenomenon found in various glomerular diseases, often resulting in end-stage renal disease. ${ }^{14}$

The aim of the present study, therefore, was to clarify the roles of the coagulation process in proliferative responses in MsPGN. The results revealed an important role of factor Xa in rat Thy-1 nephritis and the protective effect of a factor Xa inhibitor in this model.

\section{METHODS}

\section{Animals}

Six-week-old male Wistar rats weighing 180-200 g were obtained from Shimizu Laboratory Materials (Kyoto, Japan). Rats were housed under specific pathogen-free conditions at the Animal Facility of Kyoto University, Faculty of Medicine. All animal experiments were performed in accordance with institutional guidelines, and the Review Board of Kyoto University granted ethical permission for this study. DX-9065a, (2S)-2[4-[[(3S)-1-acetimidoyl-3-pyrrolidinyl] oxy]phenyl]-3-(7-amidino-2-naphthyl) propanoic acid hydro-chloride pentahydrate, was kindly provided by Daiichi Pharmaceutical Co. (Tokyo, Japan).

\section{Experimental Design}

Rat MsPGN was induced by a single injection of a mouse anti-Thy 1.1. monoclonal antibody OX-7 $(1 \mathrm{mg} / \mathrm{kg}$ body weight; Cedarlane Laboratories, Hornby, Canada) through the tail vein, as described elsewhere. ${ }^{15,16}$ For the time-course study of the expression of tissue factor, factor V, factor X, PAR2, macrophage infiltration and mesangial proliferation, rats were killed at four time points: 1, 3, 5, and 8 days after OX-7 injection. Kidney tissues were processed for ordinary light microscopy and immunohistological evaluation, as described below. For the intervention study, 24 rats were divided into four experimental groups $(n=6$, each): the normal group, injected with the same volume of physiologic saline; the disease control group, injected with OX-7; factor Xa inhibitor groups, injected with OX-7 and DX-9065a simultaneously at 2.5 (low dose), or 10 (high dose) $\mathrm{mg} / \mathrm{kg}$ body weight. All rats were killed on day 8. Before killing, 24-h urine to measure creatinine and protein levels was obtained from each rat. Blood samples and kidneys were collected at the time of killing. The prothrombin time (PT), activated partial thromboplastin time (APTT), and kidney weight were assessed.

\section{Histological Evaluation of Renal Tissue}

Kidney tissues from each animal were processed for evaluation by light and immunostaining microscopy. For light microscopy, tissues were fixed in $10 \%$ neutral-buffered formalin ( $\mathrm{pH} 7.4)$ and embedded in paraffin. Sections $(2 \mu \mathrm{m})$ were then subjected to periodic acid-Schiff staining, which was evaluated quantitatively by counting the total number of glomerular cells, the total numbers of glomeruli with mesangiolysis and capillary ballooning, respectively, and measuring areas of 20 randomly selected glomerular crosssections with NIH Image (NIH, Bethesda, MD, USA). The sections $(2 \mu \mathrm{m})$ were also reacted with a mouse monoclonal antibody against proliferative cell nuclear antigen (PCNA) using a DAKO EPOS anti-PCNA/HRP kit (DAKO Corp., Carpinteria, CA, USA), a mouse antibody against rat ED-1 (Chemicon International, Temecula, CA, USA), and a goat antibody against rat fibrinogen (ICN, Aurora, OH, USA), using an $\mathrm{ABC}$ Elite-peroxidase staining kit (Vector Laboratories, Burlingame, CA, USA). Color was then developed by incubation with a DAB Substrate kit (Pierce, Rockford, IL, USA). Sections were counterstained with hematoxylin. The average numbers of ED-1- and PCNA-positive cells in a glomerular cross-section were evaluated by enumerating the cells in 20 glomeruli in each section. The glomerular deposition of fibrin was evaluated quantitatively by measuring the areas of positive reaction in 20 selected glomerular crosssections with NIH Image, and expressed as the positive area per glomerulus.

The localization of tissue factor, factor $\mathrm{V}$, factor $\mathrm{X}$, and PAR2 was studied using fresh frozen sections $(2 \mu \mathrm{m})$. Tissue specimens frozen in OCT compound (Miles Laboratories, Elkhart, IL, USA) were cut into serial sections in a cryostat. Sections for tissue factor staining were fixed in $4 \%$ neutralbuffered formalin for $8 \mathrm{~min}$, then $100 \%$ ethanol for $2 \mathrm{~min}$, then treated in $0.025 \%$ protease VIII (Sigma, St Louis, MO, USA) for $1.5 \mathrm{~min}$ at room temperature. Sections for factor V, factor X, or PAR2 detection were fixed in acetone for $5 \mathrm{~min}$ at room temperature. These fixed sections were stained by an indirect method using a goat anti-mouse tissue factor antibody (Santa Cruz Biotechnology, Santa Cruz, CA, USA), a sheep anti-human factor $\mathrm{V}$ antibody (Cedarlane Laboratories), a goat anti-human factor $\mathrm{X}$ antibody (Santa Cruz Biotechnology), or a goat anti-mouse PAR2 antibody (Santa Cruz Biotechnology), as described previously. ${ }^{2}$ Sections were then incubated with appropriate secondary antibodies, and color was developed as mentioned above. The specificity of the anti-PAR2 antibody was previously reported by blocking test, using specific immunizing blocking peptide. ${ }^{17}$ The specificity of the anti-Factor $\mathrm{X}$ antibody was also confirmed by blocking test, using purified human Factor X (Hyphen BioMed, Neuville sur Oise, France). The reactivity of the anti-tissue factor antibody was confirmed using sections of murine uterine.

\section{Isolation of Glomeruli}

Glomeruli were isolated from the renal cortex of rats using the differential thieving method, with the purity of glomeruli over $90 \% .{ }^{18,19}$ Briefly, kidneys were gently ground through 
$400-\mu \mathrm{m}$ and then $200-\mu \mathrm{m}$ stainless steel sieves. The obtained fraction was washed with the solution on a $90-\mu \mathrm{m}$ mesh. The supernatant was then centrifuged at 1000 r.p.m. for $5 \mathrm{~min}$ at $4^{\circ} \mathrm{C}$.

\section{Western Blot Analysis of Phosphorylated p44/42 Mitogen-Activated Protein (MAP) Kinase}

Isolated glomeruli were suspended in cell lysis buffer (Cell Signaling Technology, Beverly, MA, USA) with $1 \mathrm{mM}$ phenylmethylsulfonyl fluoride for $30 \mathrm{~min}$ at $4^{\circ} \mathrm{C}$. After centrifugation of the sample, the supernatant was used as total cell lysates. In total, $20 \mu \mathrm{g}$ of each sample was applied to sodium dodecyl sulfate-polyacrylamide gel electrophoresis. After electrophoresis, the proteins were transferred to nitrocellulose filters (Schleiecher \& Schuell, Keene, NH, USA). The blots were subsequently incubated with a rabbit anti-phospho-p44/42 mitogen-activated protein (MAP) kinase antibody (Cell Signaling Technology) or a rabbit antiMAP kinase antibody (Oncogene, San Diego, CA, USA), followed by incubation with horseradish peroxidase-conjugated donkey anti-rabbit IgG (Amersham Pharmacia Biotech, Little Chalfont, UK). The final reaction was developed with a chemiluminescent system (Amersham Pharmacia Biotech).

\section{Statistical Analysis}

Values are represented as the mean \pm s.d. Comparisons among groups were performed with a two-way repeated analysis of variance using Fisher's post hoc test. Analyses were performed using the StatView program (Abacus Concepts, Berkley, CA, USA). A $P$-value $<0.05$ was considered significant.

\section{RESULTS}

Time Course of the Expressions of Tissue Factor, Factor V, and PAR2, and Total Glomerular Cell Number in Rat MsPGN

The expression of glomerular tissue factor, factor V, factor X, PAR2, and macrophage infiltration were negative or scarce in the normal group (day 0), and their expressions increased mainly in the mesangium, and were found partially along capillary loops in the disease control groups (Figure 1). Staining intensity was moderately positive for tissue factor, and intense for factor $\mathrm{V}$ on day 3 , and both were moderate on day 8 after OX-7 injection. Factor X deposition was delayed; it was detected weakly to moderately on day 3 , and significantly accumulated on day 8. PAR2 staining was significant on day 3 and day 8 . The number of total glomerular cells was reduced by necrosis on day 1 after OX-7 injection as previously reported. ${ }^{12}$ Then the number of cells began to increase, and the peak of cellular proliferation was noted on day 8 (normal, $42.6 \pm 4.1$; day 1 disease, $36.0 \pm 1.3 ; P<0.01$ vs normal; day 3 disease, $41.2 \pm 1.3$; day 5 disease, $57.1 \pm 1.5$, $P<0.01$ vs normal; day 8 disease, $83.9 \pm 4.8$ /glomerulus, $P<0.01 v s$ normal) (Figure 2a, open column). On the other hand, infiltrating macrophages were observed prominently in the initial phase of this model, and lasted during the observation period (normal, $0.0 \pm 0.0$; day 1 disease, $7.6 \pm 2.0$; day 3 disease, $5.5 \pm 1.0$; day 5 disease, $6.6 \pm 0.4$; day 8 disease, $6.5 \pm 0.4$ /glomerulus, $P<0.01$ vs normal, respectively) (Figure 2b, open column).

\section{Effect of DX-9065a on Kidney Weight and Proteinuria} When rats were killed 8 days after the injection of OX-7, total kidney weight was significantly increased in the disease control group compared with the normal group, and DX-9065a treatment markedly reduced kidney weight in a dose-dependent manner (normal, 1.84 \pm 0.12 ; disease control, $2.53 \pm 0.12$; low dose, $2.52 \pm 0.87$; high dose; $2.17 \pm 0.82 \mathrm{~g} /$ day, $P<0.01$ vs disease control). On day 8 , the amount of urinary protein was significantly increased in the disease control group and this increase was also reduced by DX-9065a treatment (normal, 15.0 \pm 1.4 ; disease control, $149.7 \pm 17.8$; low dose; $103.1 \pm 14.6, P<0.05$; high dose, $44.3 \pm 12.5 \mathrm{mg} / \mathrm{day}, P<0.01$ vs disease control) (Figure 3 ).

\section{Effect of DX-9065a on Histological Findings}

We next examined glomerular histological change in these rats after DX-9065a treatment (Figure 4a-d). Both disease control and DX-9065a treatment groups started out with an equivalent degree of mesangiolysis on day $1(24 \mathrm{~h})$ after OX-7 injection (disease control, 91.0 $\pm 6.5 \%$; high-dose of DX$9065 \mathrm{a}, 92.5 \pm 5.0 \%$ of glomeruli). The glomerular area was increased 2.4-fold after OX-7 injection compared with the normal group $(P<0.01)$. The increase in glomerular area on day 8 was markedly reduced by DX-9065a treatment in a dose-dependent manner (normal, $6.2 \pm 0.5$; disease control, $15.0 \pm 1.1 ; \quad$ low dose, $13.6 \pm 5.3, \quad P<0.01$; high dose $9.7 \pm 0.8 \times 10^{3} \mu \mathrm{m}^{2}, P<0.01$ vs disease control). As shown in the time-course study, the total glomerular cell number was increased after OX-7 injection (Figure 2a, open column), and this increase was suppressed by DX-9065a treatment (day 1 treatment, $35.8 \pm 1.0$; day 3 treatment, $35.7 \pm 1.3, P<0.01$ vs disease control; day 5 treatment, $48.1 \pm 0.9, P<0.01$ vs

Figure 1 Time course of the expression of macrophage, tissue factor, factor V, factor $X$, and PAR2 staining in Thy- 1 nephritis. Macrophage is abundant both on day $3(\mathbf{b})$ and day 8 (c); tissue factor is moderately positive both on day $3(\mathbf{e})$ and day 8 (f); factor $V$ is intensely on day $3(\mathbf{h})$, and moderately positive on day 8 (i); factor $\mathrm{X}$ is mildly on day $3(\mathbf{k})$ and intensely positive on day 8 (I); PAR2 is both prominent on days 3 (n) and 8 (o) in the disease control groups, whereas such staining is negative or scarce in the normal group $(\mathbf{a}, \mathbf{d}, \mathbf{g}, \mathbf{j}$, and $\mathbf{m}$, respectively). Original magnification for all panels $\times 400$. 
Day 0
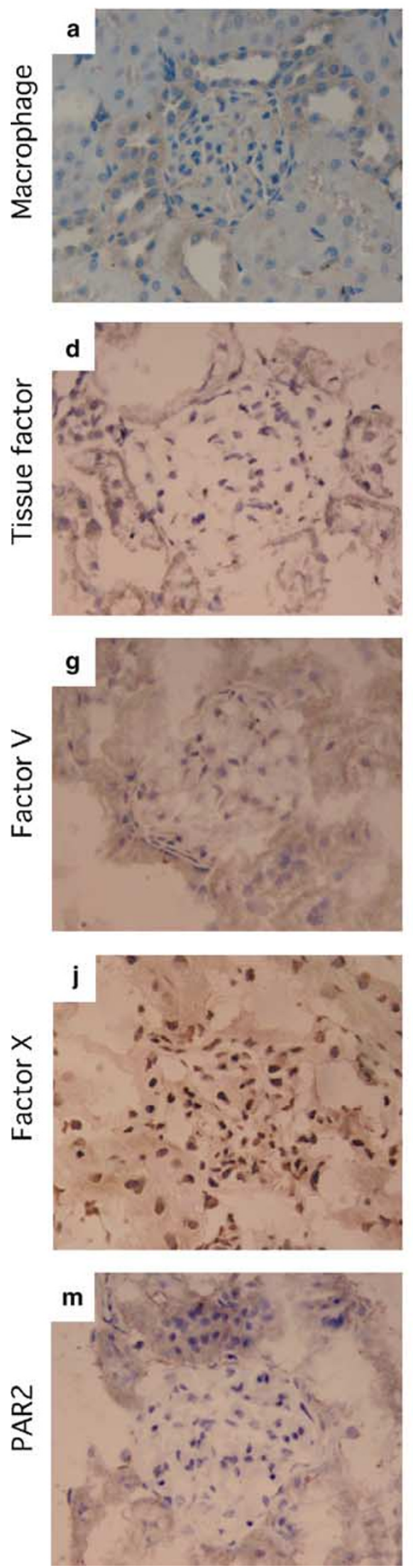

Day 3
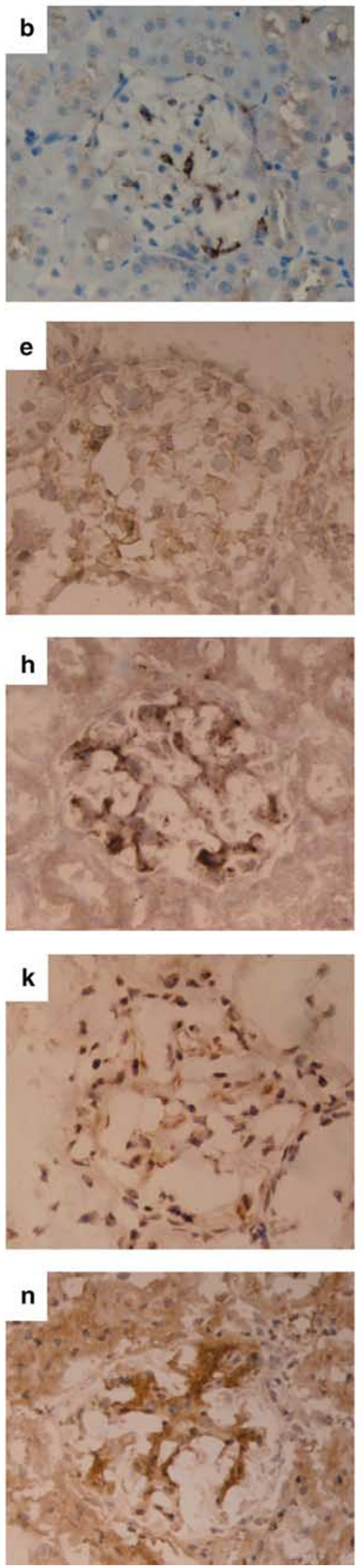

Day 8
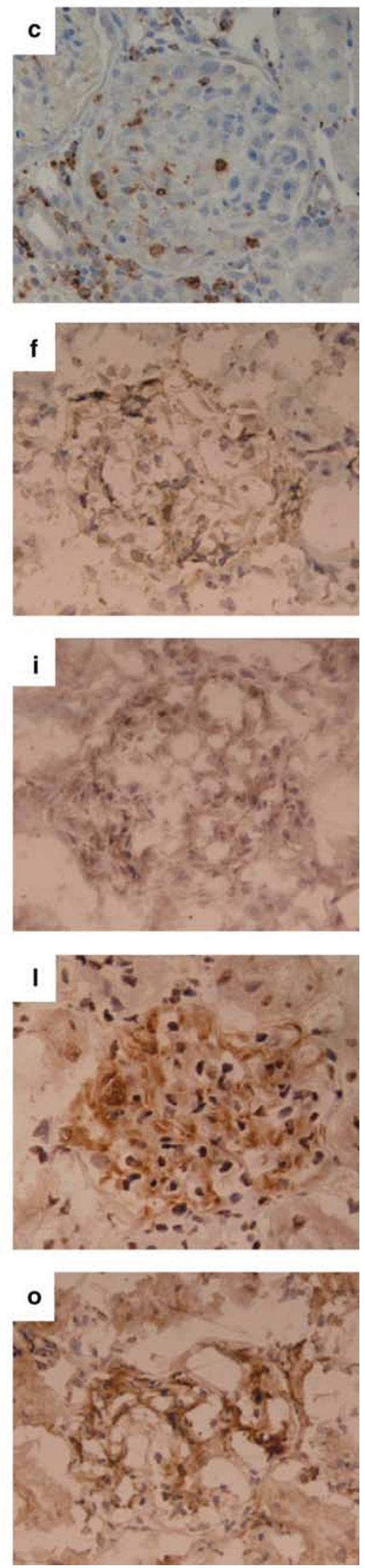
disease control; day 8 treatment, $67.4 \pm 5.5 /$ glomerulus, $P<0.01$ vs disease control) (Figure 2a, closed column). DX9065a treatment did not delay glomerular repair, as shown by the ratio of residual capillary ballooning in glomeruli on day 8 (disease control, $26.5 \pm 5.0 \%$; high-dose treatment, $22.5 \pm 6.0 \%$ of glomeruli; no significant difference). The dose-dependent inhibitory effect on cellular proliferation was noted as shown in Figure 4e with suppression by low-dose treatment $(66.7 \pm 5.4$ /glomerulus, $P<0.01$ vs disease control). In contrast, abundant macrophages rapidly infiltrated on day 1 and subsequently persisted (Figure $2 \mathrm{~b}$, open column). This increase was reduced by DX-9065a treatment on days 5 and 8 (day 1 treatment, $7.2 \pm 0.7$; day 3 treatment, $4.7 \pm 0.9$; day 5 treatment, $3.7 \pm 1.3, P<0.01$ vs disease control; day 8 treatment, $3.6 \pm 1.0 /$ glomerulus, $P<0.01 v s$ disease control) (Figure 2b, closed column).

Figure 5 shows a significant increase in crescent formation after OX-7 injection compared with the untreated group, in which no crescent formation was observed. This cellular crescent formation induced by OX-7 was suppressed by DX-9065a (normal, $0.00 \pm 0.00$; disease control, $4.9 \pm 0.6$; low dose, $3.2 \pm 0.8$; high dose, $1.7 \pm 0.3 / 20$ glomeruli, $P<0.01$ vs disease control).
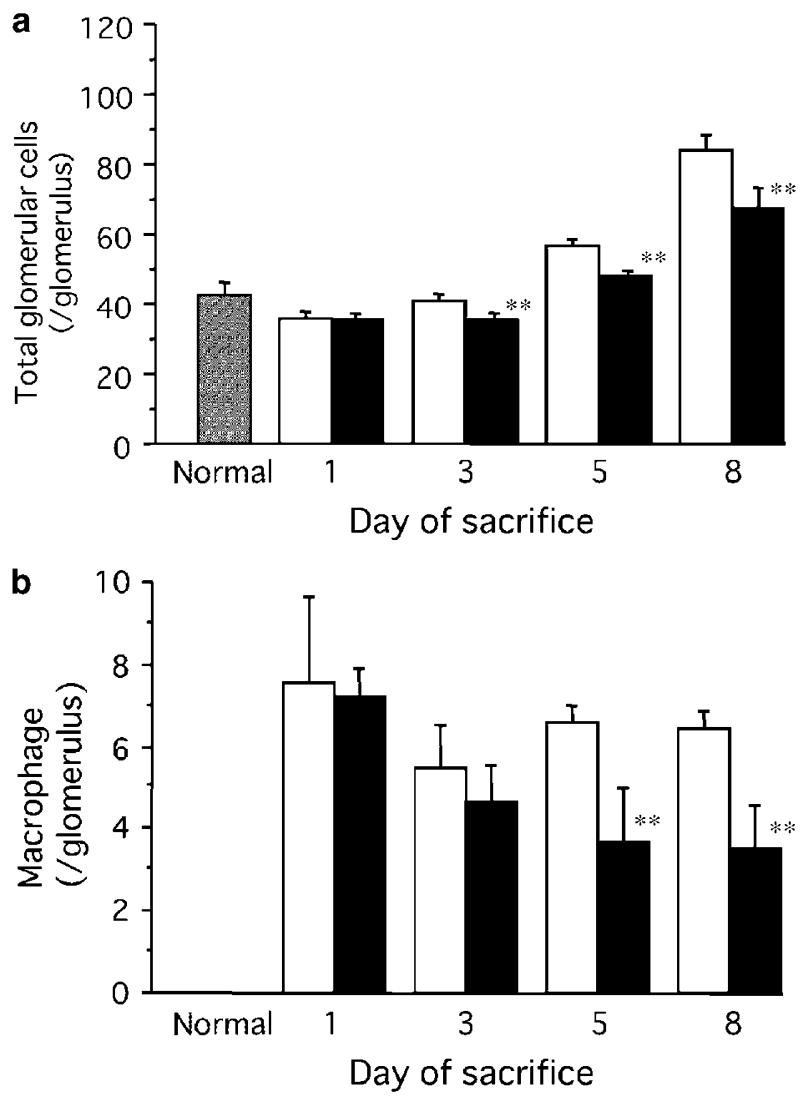

Figure 2 Time course of the number of total glomerular cells (a) and infiltrating macrophages (b) in Thy-1 nephritis. Normal group, gray column; disease control group, open column; and DX-9065a-treated group, closed column. ${ }^{* * P}<0.01$ vs disease control on each day (six rats per group).
To assess proliferating cells in this model, we counted PCNA-positive cells in the glomerulus. The PCNA-positive cell number was significantly increased 8 days after OX-7 injection (Figure 6). The increased PCNA-positive cell number induced by OX-7 injection was significantly suppressed by DX-9065a (normal, 1.1 \pm 0.6 ; disease control, $22.0 \pm 5.5$; low dose, $22.9 \pm 2.3$; high dose, $12.9 \pm 3.4 / 20$ glomeruli, $P<0.01$ vs disease control).

\section{Effects of DX-9065a on Fibrin-Related Antigen Deposition}

We then examined whether DX-9065a affects fibrin deposition in Thy-1 nephritis. Immunohistochemical analysis revealed massive fibrin deposits in the mesangium and partially along capillary loops after OX-7 injection. Fibrin deposition was significantly inhibited by high-dose DX-9065a treatment (normal, $0.6 \pm 0.3$; disease control, $14.1 \pm 6.2$; low dose, 11.6 $\pm 3.0, P<0.05$; high dose, $8.9 \pm 2.3 \%$ of glomerular area, $P<0.05$ vs disease control) (Figure 7).

\section{Effect of DX-9065a on the Phosphorylation of p44/42 MAP Kinase}

As p44/42 MAP kinase is known to be activated in Thy-1 nephritis, we examined whether p44/42 MAP kinase could be phosphorylated in this model, and whether DX-9065a treatment could affect phosphorylation. Phosphorylation of p44/42 MAP kinase in the glomerular lysates began on day 1, and continued through day 8. By densitometric analysis, markedly elevated levels of p44/42 MAP kinase phosphorylation were confirmed in disease control (normal, $0.2 \pm 0.1$; day $1,0.7 \pm 0.1$; day $3,0.7 \pm 0.1$; day $5,0.6 \pm 0.2$; day 8 , $0.6 \pm 0.2$; each $P<0.01$ vs normal). DX-9065a abolished the phosphorylation of p44/42 MAP kinase on day 8 (normal, $0.2 \pm 0.1$; disease control, $0.6 \pm 0.2$; high dose, $0.4 \pm 0.2$, $P<0.05$ vs disease control) (Figure 8 ).

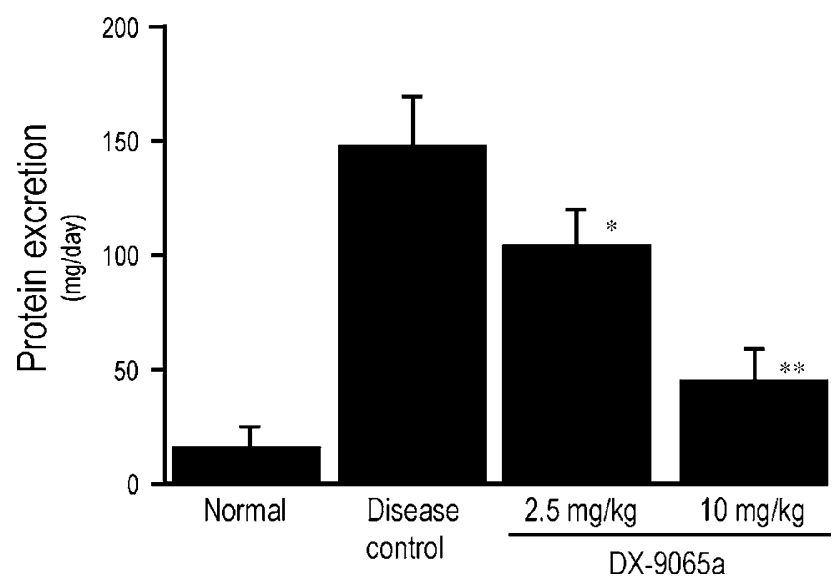

Figure 3 Effects of DX-9065a on urinary protein excretion in Thy-1 nephritis. The amount of urinary protein was significantly reduced in DX-9065a-treated rats. ${ }^{*} P<0.05,{ }^{*} P<0.01$ vs disease control (six rats per group). 

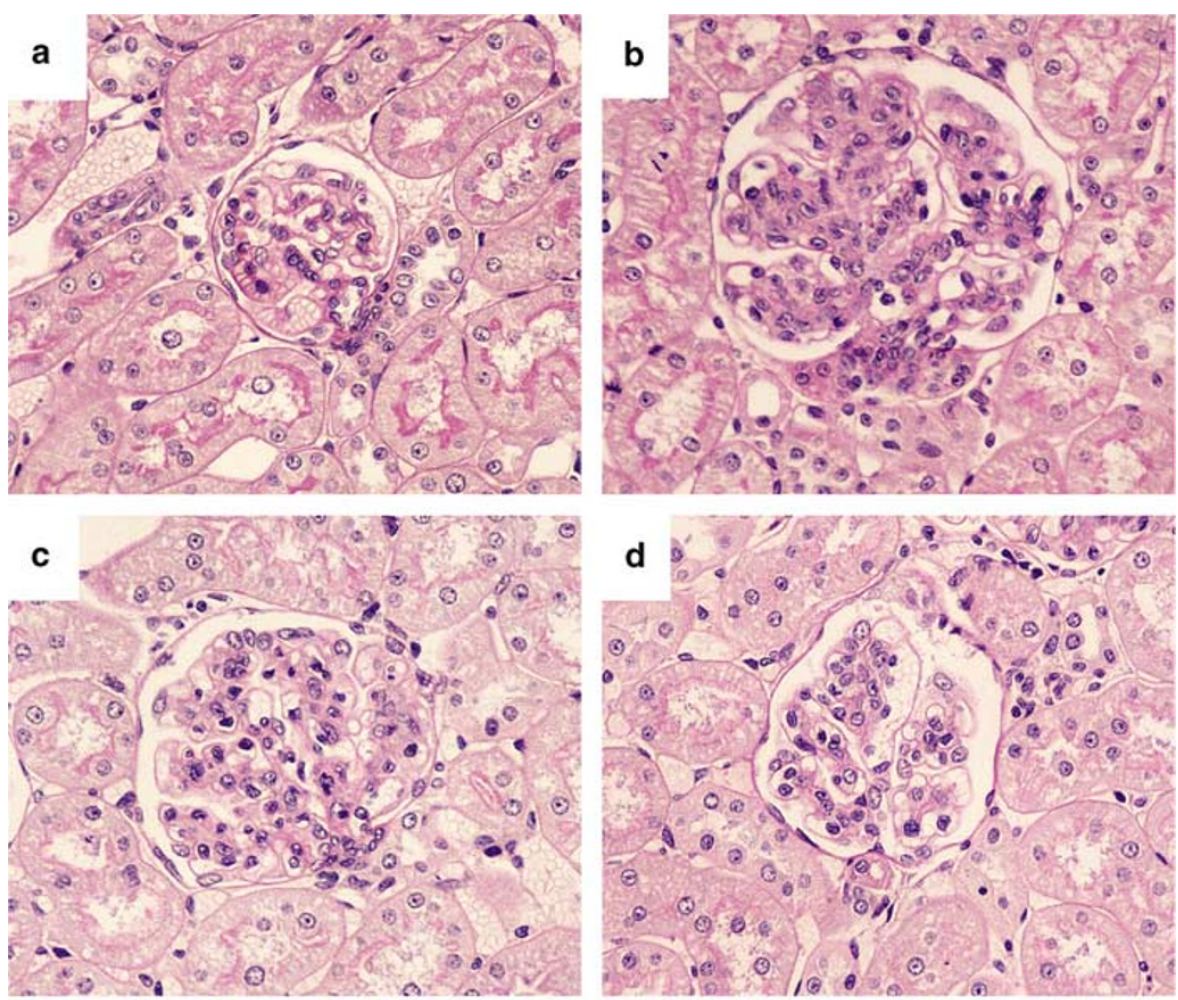

e

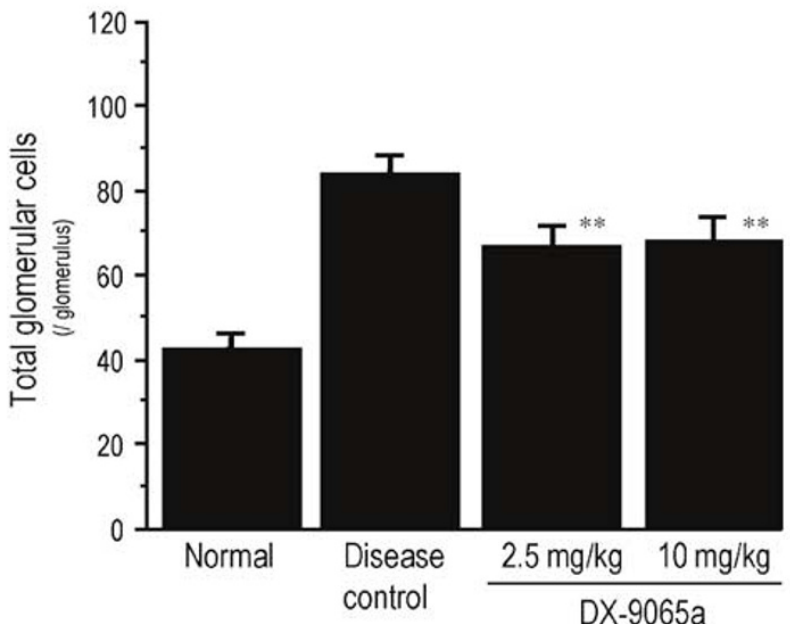

Figure 4 Inhibitory effects of DX-9065a on the total glomerular cell number. The total glomerular cell number was increased in the disease control group (b) and DX-9065a-treated groups (low dose, c; high dose, d), compared with the normal group (a). A marked reduction of total glomerular cell number in DX-9065a-treated rats was observed (e). ${ }^{*} P<0.01$ vs disease control (six rats per group). Original magnification for all panels $\times 400$.

\section{DISCUSSION}

In this study, we found that glomerular tissue factor, factor $\mathrm{V}$, and PAR2 were expressed intensely in the mesangium early, followed by factor $\mathrm{X}$ accumulation and mesangial cell proliferation in the disease control group. We also found that a specific factor Xa inhibitor, DX-9065a, could ameliorate the characteristic features of rat Thy-1 nephritis: proteinuria, mesangial cell proliferation, fibrin deposition, macrophage infiltration, and crescent formation, suggesting a role of factor $\mathrm{Xa}$ in the inflammation along with intramesangial coagulation. Our data indicate the role of p42/44 MAP kinase as a major signaling molecule in the proliferating process of Thy- 1 nephritis through factor Xa activation.

In human MsPGN, mesangial proliferation with expression of the extracellular matrix is a common pathological finding. ${ }^{20}$ Intraglomerular coagulation with fibrin deposition was suggested to be involved in the development of glomerular injury. ${ }^{21}$

Among various coagulation factors, tissue factor is known to be the principle initiator of the extrinsic coagulation 

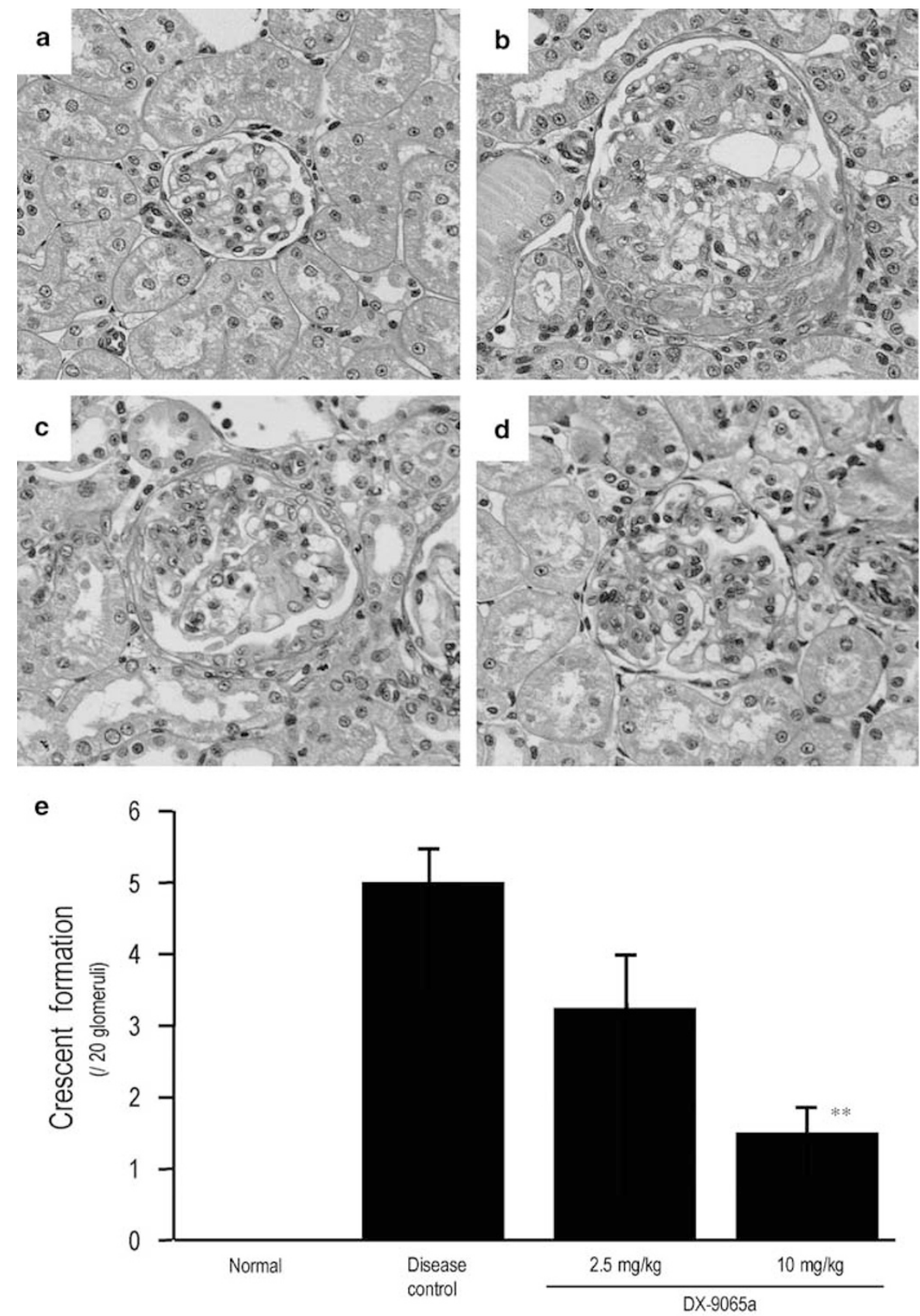

Figure 5 Inhibitory effects of DX-9065a on crescent formation. Cellular crescents are clearly detected in the disease control group (b) and DX-9065a-treated groups (low dose, $\mathbf{c}$; high dose, d), compared with the normal group (a). Significant effects of DX-9065a on the suppression of crescent formation are observed in a dose-dependent manner (e). ${ }^{*} P<0.01$ vs disease control (six rats per group). Original magnification for all panels $\times 400$.

pathway, and the glomerular expression of tissue factor is upregulated in human and rabbit crescentic glomerulonephritis. ${ }^{22,23}$ Tissue factor starts the extrinsic coagulation pathway, which activates coagulation factor $\mathrm{X}$ to factor $\mathrm{Xa}$, and factor $\mathrm{V}$ is a cofactor for prothrombin activation by factor $\mathrm{Xa}^{24}$ Tissue factor and factor $\mathrm{V}$ are produced in mesangial cells by inflammatory stimulation. ${ }^{3,25}$ In our previous study, factor $\mathrm{V}$ mRNA expression was observed in mesangial cells of IgA nephropathy with activity. ${ }^{2}$ Taken together, the activation of local coagulation in the mesangial area may progress in MsPGN. Hung H-L and High KA reported that liver contained the highest amounts of factor X mRNA; however, factor $\mathrm{X}$ was also detected in various organs, including the kidney, at trace level. ${ }^{26}$ In this context, although mesangial cells actually do not produce factor $\mathrm{X}$ under physiological conditions, they could produce factor $\mathrm{X}$ under 


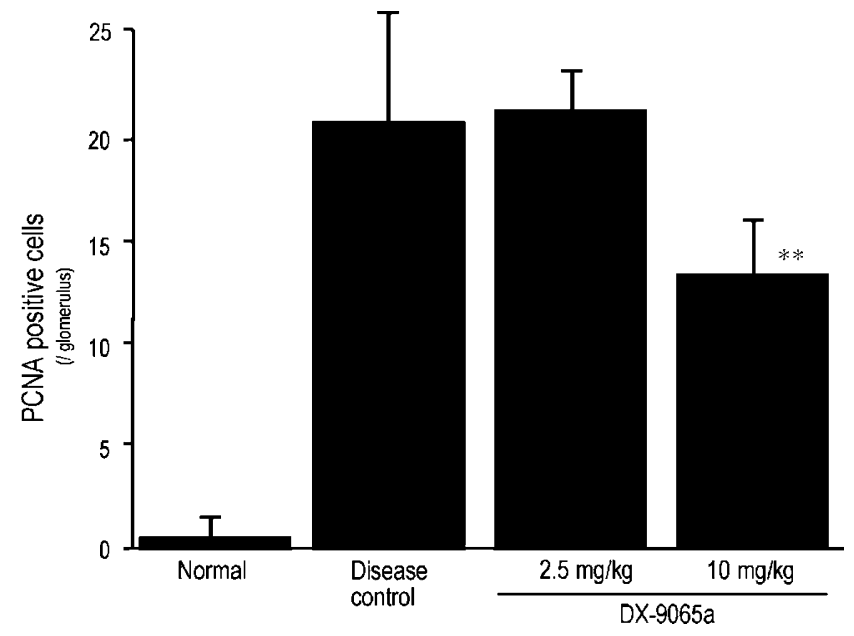

Figure 6 Inhibitory effects of DX-9065a on PCNA-positive cell number. PCNA-positive cells were often observed in glomeruli in the disease control group, whereas these cells were scarce in the normal group. PCNA-positive cell number was significantly suppressed by DX-9065a treatment in a dosedependent manner. ${ }^{*} P<0.01$ vs disease control (six rats per group).

diseased conditions. As factor $\mathrm{X}$ is produced mainly by hepatocytes in vivo, and circulates in blood vessels, ${ }^{27}$ it was suspected in the present study that factor X was supplied, at least partly, through the fenestration of endothelial cells from blood circulation, activated by tissue factor expression of the mesangial cells, and then maintained in the mesangial area by factor $\mathrm{V}$.

Factor Xa is not only a key factor in coagulation cascades but also a potent mitogen for endothelial and smooth muscle cells. ${ }^{6}$ In addition, factor Xa also stimulates the production of inflammatory cytokines, such as monocyte chemoattractant protein-1 which induces macrophage infiltration, together with interleukin- 6 and -8 , in endothelial cells. ${ }^{6}$ In the present study, there were no differences in total glomerular cell number, necrosis, or mesangiolysis between the disease control group and DX-9065a treatment group on day 1, and cellular proliferation was reduced by DX-9065a treatment on days 3, 5, and 8. Although macrophage infiltration was rapidly observed on day 1 and was not inhibited on days 1-3 by DX-9065a treatment (factor X independent), it was suppressed on days $5-8$ by the treatment (factor $\mathrm{X}$ dependent). These data suggest that DX-9065a administration on the day of OX-7 injection did not inhibit the nephritis trigger, but suppressed the following inflammation. It was noteworthy that DX-9065a treatment did not delay repair after mesangiolysis by OX-7 injection, as shown by the equal ratio of residual capillary ballooning with disease control group on day 8. Recently Murayama et al reported that higher levels of radioactivity were observed in the kidney and liver after a single intravenous dosing of $\left[{ }^{14} \mathrm{C}\right]-\mathrm{DX}-9065 \mathrm{a}$ to male rats, compared with serum concentration. In their report, the radioactivity concentration of DX-9065a in the kidney was approximately 50 times greater than the serum level $24 \mathrm{~h}$ after the single intravenous injection. ${ }^{28}$ Therefore, DX-9065a administered simultaneously with OX-7 injection might remain in renal tissue for a long time at sufficient concentration to suppress local factor Xa activity.

Crescent formation was suppressed as well as fibrin deposition and cellular proliferation in the present study. Clinically, crescent formation is observed frequently in human microscopic polyangiitis ${ }^{29,30}$ and occasionally in the active type of human MsPGN such as IgA nephropathy and Henoch-Schönlein purpura nephritis. ${ }^{31}$ Fibrin is considered to be chemotactic for leukocytes. ${ }^{32}$ Where the crescent is formed, fibrin, $\mathrm{T}$ cells, macrophages, and tissue factor are consistently observed. ${ }^{33-35}$ Although Thy-1 nephritis is basically MsPGN, crescents were observed in some studies of Thy- 1 nephritis as reported by us and another study group. ${ }^{13,36,37}$ In our previous study, treatment with prednisolone for rat Thy-1 nephritis inhibited both crescent formation and mesangial cell proliferation, although prednisolone does not suppress fibrin precipitation in Bowman's space; $^{36}$ therefore, the use of a specific factor Xa inhibitor may take advantage of antithrombotic and antiproliferative effects in crescent formation in MsPGN.

It is well known that the MAP kinase cascade plays an important role in cellular proliferation, ${ }^{38}$ and this cascade is shown to be a major intracellular mediator of proliferative response in glomerulonephritis in vivo. ${ }^{39}$ In this study, we examined whether p44/42 MAP kinase is activated in Thy- 1 nephritis, and whether this activation is suppressed by a factor Xa inhibitor. Phosphorylation of p44/42 MAP kinase was markedly increased in the glomerulus in this nephritis, and the increase was suppressed by DX-9065a treatment. Sadlier et $a l^{40}$ observed increased gene expressions of cell cycle proteins situated downstream of the MAP kinase cascade in the proliferative phase of this model of nephritis. Thrombin and factor Xa activate a novel family of cell-surface receptors, PARs, which are G protein-coupled receptors. ${ }^{41,42}$ After selective cleavage of the receptors by these serine proteases, PARs mediated signaling, and thereby exerted various cellular effects that induced inflammatory responses to tissue injury. ${ }^{43-45}$ Several in vitro studies have demonstrated that PAR2 can mediate factor Xa signaling, but not thrombin signaling. ${ }^{46}$ In our recent study, we reported that PAR2 is expressed in cultured human mesangial cells, and that factor Xa induces cellular proliferation through the activation of ERK via PAR2. ${ }^{7}$ In this study, high-dose DX-9065a suppressed both PCNA-positive cells and total glomerular cells, whereas a low dose of this inhibitor suppressed only total glomerular cells on day 8. Regarding this discrepancy, it was suspected that sufficient concentration of DX-9065a in renal tissue to suppress PCNA-positive cells in the later phase of nephritis might be maintained only by a high dose, and that the concentration from a low-dose injection might suppress only cellular proliferation in the early phase, and subsequently total glomerular cells in the later phase, but might 

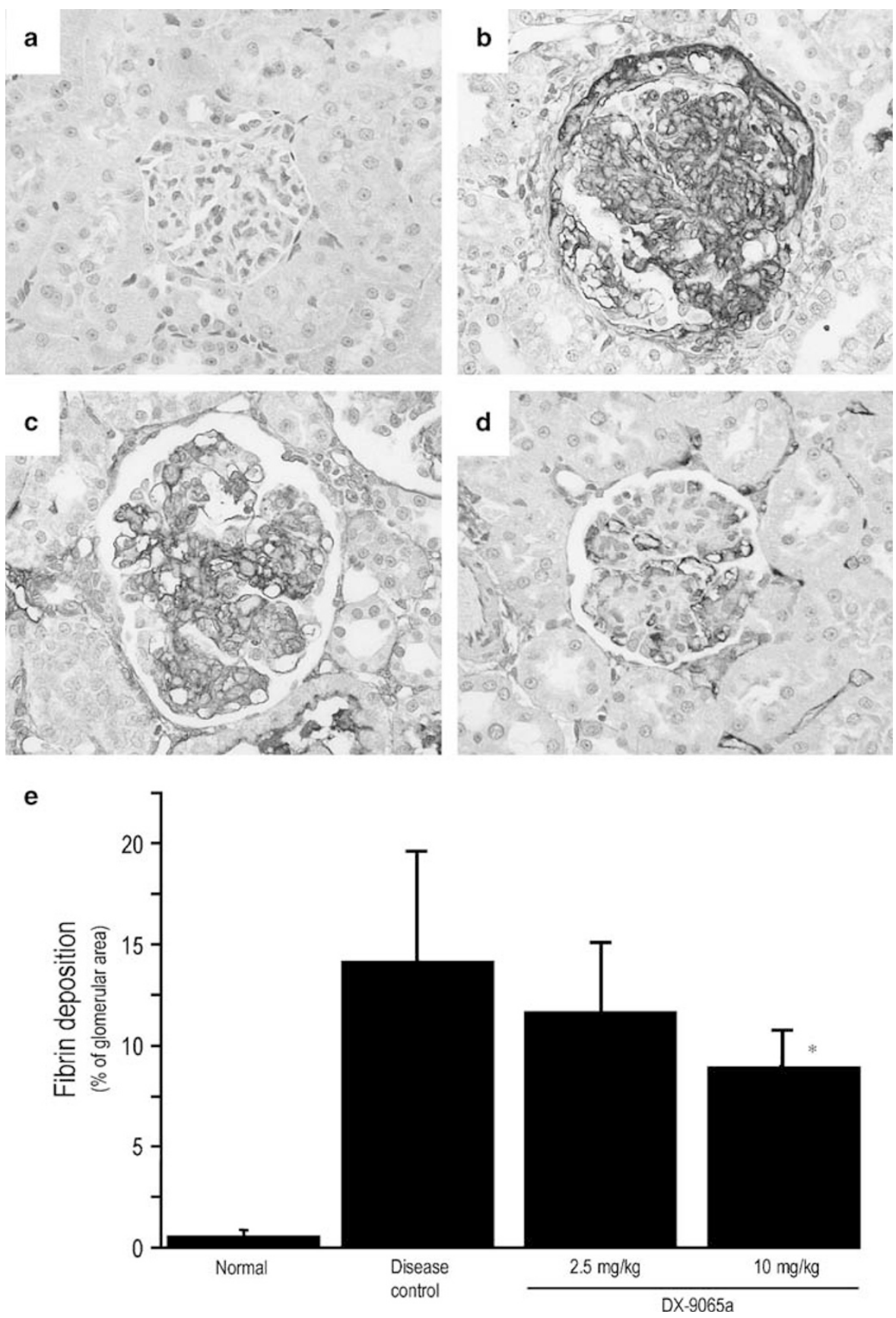

Figure 7 Inhibitory effects of DX-9065a on fibrin deposition. Fibrin deposition was intense in the disease control group (b) and DX-9065a-treated groups (low dose, c; high dose, d), compared to the normal group (a). Fibrin deposition in the mesangium, and partially along capillary loops, was reduced in DX-9065a-treated rats in a dose-dependent manner (e). ${ }^{*} P<0.05$ vs disease control (six rats per group). Original magnification for all panels $\times 400$.

not be sufficient for PCNA-positive cells to remain in the later phase on day 8 . In Thy-1 nephritis, proliferating cells in the mesangial area are mainly mesangial cells; ${ }^{47}$ therefore, it is suspected that mesangial cell proliferation is induced partly by factor Xa through PAR2 activation in vivo, as shown previously in cultured mesangial cells. In the present study, PAR2 was scarcely observed on day 0 , and was high on day 3 and day 8. Grandaliano et $a l^{48}$ reported that PAR2-positive cells are not observed in glomeruli in human IgA nephropathy, although such positive cells are abundant in tubular epithelial cells. As PAR2 expression in cultured fibroblasts was suppressed within the collagen matrix, ${ }^{49}$ the disappearance of PAR2-positive cells from glomeruli in the chronic phase of human glomerulonephritis may be induced by downregulation after the production of extracellular matrix proteins. Further study should be conducted to clarify 

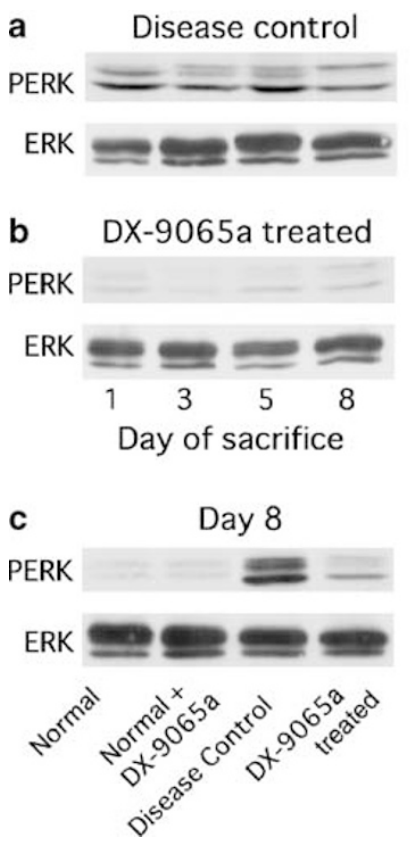

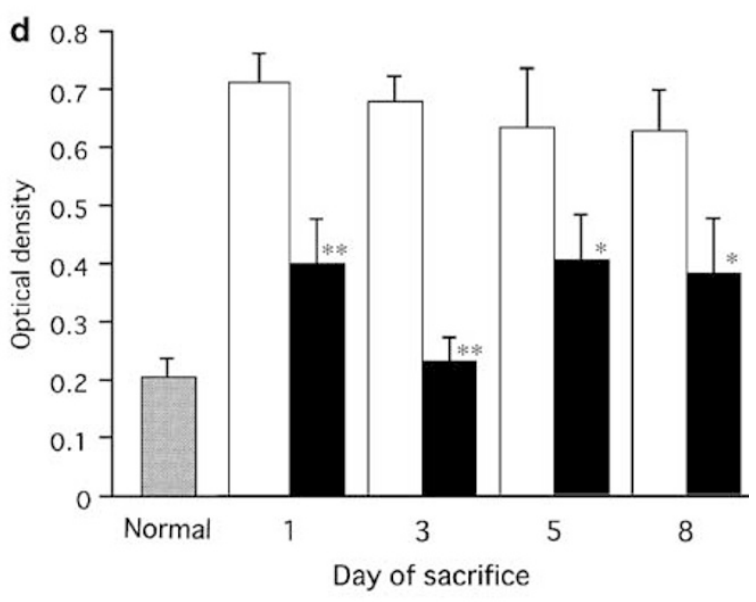

Figure 8 Phosphorylation of ERK and its inhibition by DX-9065a. Time course of phosphorylated p44/42 MAP kinase in the glomerular lysates of disease control and DX9065a-treated groups is shown in (a) and (b), respectively. Levels of phosphorylated of $p 44 / 42$ MAP kinase on day 8 are shown in (c). By densitometric analysis, phospholylation of p44/ 42 MAP kinase began on day 1 and continued through day 8 , while they are suppressed by DX9065a treatment (d). Normal group, gray column; disease control group, open column; and DX9065a-treated group, closed column. ${ }^{*} P<0.05$, ${ }^{* *} P<0.01$ vs disease control (six rates per group). the sequence of events from factor Xa activation to the decrease of PAR2-positive cells.

In conclusion, the results of the present study suggest that tissue factor and factor $\mathrm{V}$ induction may accelerate MsPGN, at least partly, through the activation and accumulation of factor X via proinflammatory and procoagulant mechanisms, and the inhibition of this pathway with a specific factor $\mathrm{Xa}$ inhibitor is a promising method to regulate the disease process.

\section{ACKNOWLEDGEMENTS}

We are grateful to Ms Fumie Uemura for secretarial support, to Ms Yukiko Kato and Ms Rie Hikawa for technical support, and to Mr Daniel Mrozek for help in preparing the manuscript. This study was supported by a grant from Daiichi Pharmaceuticals, Japan, and a grant for 'Research on Regulatory Science of Pharmaceuticals and Medical Devices' by Ministry of Health, Labor, and Welfare in Japan.

1. Kincaid-Smith P. Coagulation and renal disease. Kidney Int 1972;4: 183-190.

2. Liu N, Ono T, Suyama K, et al. Mesangial factor V expression colocalized with fibrin deposition in IgA nephropathy. Kidney Int 2000;58:598-606.

3. Ono $\mathrm{T}$, Liu $\mathrm{N}$, Kasuno $\mathrm{K}$, et al. Coagulation process proceeds on cultured human mesangial cells via expression of factor V. Kidney Int 2001;60:1009-1017.

4. Monno R, Grandaliano G, Faccio R, et al. Activated coagulation factor X: a novel mitogenic stimulus for human mesangial cells. J Am Soc Nephrol 2001;12:891-899.

5. Herault JP, Bono F, Avril C, et al. Activation of human vascular endothelial cells by factor Xa: effect of specific inhibitors. Biochem Pharmacol 1999;57:603-610.

6. Senden $\mathrm{NH}$, Jeunhomme TM, Heemskerk JW, et al. Factor Xa induces cytokine production and expression of adhesion molecules by human umbilical vein endothelial cells. J Immunol 1998;161:4318-4324.

7. Tanaka $M$, Arai $\mathrm{H}$, Liu $\mathrm{N}$, et al. Role of coagulation factor $\mathrm{Xa}$ and protease-activated receptor 2 in human mesangial cell proliferation. Kidney Int 2005;67:2123-2133.
8. Hara T, Yokoyama A, Ishihara $H$, et al. DX-9065a, a new synthetic, potent anticoagulant and selective inhibitor for factor Xa. Thromb Haemost 1994;71:314-319.

9. Kaiser B, Paintz M, Scholz O, et al. A synthetic inhibitor of factor Xa, DX-9065a, reduces proliferation of vascular smooth muscle cells in vivo in rats. Thromb Res 2000;98:175-185.

10. Alexander $\mathrm{JH}$, Dyke $\mathrm{CK}$, Yang $\mathrm{H}$, et al. Initial experience with factor-Xa inhibition in percutaneous coronary intervention: the XaNADU-PCI Pilot. J Thromb Haemost 2004;2:234-241.

11. Bagchus WM, Hoedemaeker PJ, Rozing J, et al. Glomerulonephritis induced by monoclonal anti-Thy 1.1 antibodies. A sequential histological and ultrastructural study in the rat. Lab Invest 1986;55:680-687.

12. Mosley K, Collar J, Cattell V. Mesangial cell necrosis in Thy 1 glomerulonephritis-an ultrastructural study. Virchows Arch 2000;436:567-573.

13. Oyanagi $A$, Orikasa $M$, Kawachi $H$, et al. Crescent-forming mechanism in an irreversible Thy-1 model in rats. Nephron 2001;89:439-447.

14. Klahr S, Schreiner G, Ichikawa I. The progression of renal disease. N Engl J Med 1988;318:1657-1666.

15. Nagasawa $Y$, Takenaka M, Matsuoka $Y$, et al. Quantitation of mRNA expression in glomeruli using laser-manipulated microdissection and laser pressure catapulting. Kidney Int 2000;57:717-723.

16. Bokemeyer D, Ostendorf $T$, Kunter $U$, et al. Differential activation of mitogen-activated protein kinases in experimental mesangioproliferative glomerulonephritis. J Am Soc Nephrol 2000; 11:232-240.

17. Lan RS, Stewart GA, Goldie RG, et al. Altered expression and in vivo lung function of protease-activated receptors during influenza $A$ virus infection in mice. Am J Physiol Lung Cell Mol Physiol 2004;286:L388-L398.

18. Ziswiler R, Steinmann-Niggli K, Kappeler A, et al. Mycophenolic acid: a new approach to the therapy of experimental mesangial proliferative glomerulonephritis. J Am Soc Nephrol 1998;9:2055-2066.

19. Pippin JW, Qu Q, Meijer $\mathrm{L}$, et al. Direct in vivo inhibition of the nuclear cell cycle cascade in experimental mesangial proliferative glomerulonephritis with Roscovitine, a novel cyclin-dependent kinase antagonist. J Clin Invest 1997;100:2512-2520.

20. Oomura A, Nakamura T, Arakawa $\mathrm{M}$, et al. Alteration in the extracellular matrix components in human glomerular diseases. Virchows Arch A Pathol Anat Histopathol 1989;415:151-159.

21. Vassalli P, McCluskey RT. The pathogenetic role of coagulation process in glomerular diseases of immunological origin. Adv Nephrol Necker Hosp 1971;1:47-63. 
22. Tipping PG, Dowling JP, Holdsworth SR. Glomerular procoagulant activity in human proliferative glomerulonephritis. J Clin Invest 1988;81:119-125.

23. Tipping PG, Erlich JH, Apostolopoulos J, et al. Glomerular tissue factor expression in crescentic glomerulonephritis. Correlations between antigen, activity, and mRNA. Am J Pathol 1995;147: 1736-1748.

24. Mann KG, Jenny RJ, Krishnasway S. Cofactor proteins in the assembly and expression of blood clotting enzyme complexes. Annu Rev Biochem 1988;57:915-956.

25. Wiggins RC, Njoku N, Sedor JR. Tissue factor production by cultured rat mesangial cells. Stimulation by TNF alpha and lipopolysaccharide. Kidney Int 1990;37:1281-1285.

26. Hung $\mathrm{H}-\mathrm{L}$, High KA. Liver-enriched transcription factor HNF-4 and ubiquitous factor NF-Y are critical for expression of blood coagulation factor X. J Biol Chem 1996;274:2323-2331.

27. Wright DJ, Morris DP, Stafford DW. Vitamin K-dependent gammaglutamyl carboxylase. In: High KA, Roberts HR (eds). Molecular Basis of Thrombosis and Hemostasis. Marcel Dekker: New York, 1995, pp 309-329.

28. Murayama N, Nakaoka M, Sudo K. Contribution of lysosomes to concentrative uptake of DX-9065a into rat liver. J Pharm Sci 2006;95:1763-1770.

29. Cunningham MA, Ono T, Hewitson TD, et al. Tissue factor pathway inhibitor expression in human crescentic glomerulonephritis. Kidney Int 1999;55:1311-1318.

30. Ono T, Kanatsu K, Ueda S, et al. Detection of the antigenicity of the D-dimer of cross linked fibrin in the glomerulus by plasmin treatment. Kidney Int 1994;46:260-265.

31. Ono T, Muso E, Suyama K, et al. Intraglomerular deposition of intact cross-linked fibrin in IgA nephropathy and Henoch-Schönlein purpura nephritis. Nephron 1996;74:522-528.

32. Morita T, Suzuki Y, Churg J. Structure and development of the glomerular crescent. Am J Pathol 1973;72:349-368.

33. Erlich $\mathrm{JH}$, Holdsworth SR, Tipping PG. Tissue factor initiates glomerular fibrin deposition and promotes major histocompatibility complex class II expression in crescentic glomerulonephritis. Am J Pathol 1997; 150:873-880.

34. Tipping PG, Holdsworth SR. The participation of macrophages, glomerular procoagulant activity, and factor VIII in glomerular fibrin deposition. Studies on anti-GBM antibody-induced glomerulonephritis in rabbits. Am J Pathol 1986;124:10-17.
35. Neale TJ, Tipping PG, Carson SD, et al. Participation of cell-mediated immunity in deposition of fibrin in glomerulonephritis. Lancet 1988;2:421-424.

36. Ono $\mathrm{T}$, Liu N, Makino $\mathrm{T}$, et al. Role of mesangial Factor $\mathrm{V}$ expression in the crescent formation in rat experimental mesangioproliferative glomerulonephritis. J Pathol 2004;204:229-238.

37. Kriz W, Hahnel $\mathrm{B}$, Hosser $\mathrm{H}$, et al. Pathways to recovery and loss of nephrons in anti-Thy-1 nephritis. J Am Soc Nephrol 2003;14: 1904-1926.

38. Bokemeyer D, Sorokin A, Dunn MJ. Multiple intracellular MAP kinase signaling cascades. Kidney Int 1996;49:1187-1198.

39. Bokemeyer D, Panek D, Kramer HJ, et al. In vivo identification of the mitogen-activated protein kinase cascade as a central pathogenic pathway in experimental mesangioproliferative glomerulonephritis. J Am Soc Nephrol 2002;13:1473-1480.

40. Sadlier DM, Ouyang X, McMahon B, et al. Microarray and bioinformatic detection of novel and established genes expressed in experimental anti-Thy1 nephritis. Kidney Int 2005;68:2542-2561.

41. Macfarlane SR, Seatter MJ, Kanke T, et al. Proteinase-activated receptors. Pharmacol Rev 2001;53:245-282.

42. Ossovskaya VS, Bunnett NW. Protease-activated receptors: contribution to physiology and disease. Physiol Rev 2004;84:579-621.

43. Grand RJ, Turnell AS, Grabham PW. Cellular consequences of thrombin-receptor activation. Biochem J 1996;313(Part 2):353-368.

44. Coughlin SR. Thrombin signalling and protease-activated receptors. Nature 2000;407:258-264.

45. Dugina TN, Kiseleva EV, Chistov IV, et al. Receptors of the PAR family as a link between blood coagulation and inflammation. Biochemistry (Mosc) 2002;67:65-74.

46. Camerer $\mathrm{E}$, Kataoka $\mathrm{H}, \mathrm{Kahn} \mathrm{M}$, et al. Genetic evidence that proteaseactivated receptors mediate factor Xa signaling in endothelial cells. J Biol Chem 2002;277:16081-16087.

47. Floege J, Johnson RJ, Gordon K, et al. Increased synthesis of extracellular matrix in mesangial proliferative nephritis. Kidney Int 1991;40:477-488.

48. Grandaliano G, Pontrelli P, Cerullo G, et al. Protease-activated receptor2 expression in $\lg A$ nephropathy: a potential role in the pathogenesis of interstitial fibrosis. J Am Soc Nephrol 2003;14:2072-2083.

49. Gruber BL, Marchese MJ, Santiago-Schwarz F, et al. Protease-activated receptor-2 (PAR-2) expression in human fibroblasts is regulated by growth factors and extracellular matrix. J Invest Dermatol 2004;123:832-839. 